\title{
The Use of Multivariate Data Analysis (HCA and PCA) to Characterize Ashes from Biomass Combustion
}

\author{
${\text { Małgorzata Szczepanik }{ }^{1} \mathbb{D} \text {, Joanna Szyszlak-Bargłowicz }}^{2, *} \mathbb{D}$, Grzegorz Zając ${ }^{2} \mathbb{D}$, Adam Koniuszy $^{3} \mathbb{D}$, \\ Małgorzata Hawrot-Paw ${ }^{3}$ (D) and Artur Wolak 4 (D)
}

1 Department of Applied Mathematics and Computer Science, Faculty of Production Engineering, University of Life Sciences in Lublin, Głeboka 28, 20-612 Lublin, Poland; malgorzata.szczepanik@up.lublin.pl

2 Department of Power Engineering and Transportation, Faculty of Production Engineering, University of Life Sciences in Lublin, Głeboka 28, 20-612 Lublin, Poland; grzegorz.zajac@up.lublin.pl

3 Department of Renewable Energy Engineering, West Pomeranian University of Technology, Papieża Pawła VI 1, 71-459 Szczecin, Poland; adam.koniuszy@zut.edu.pl (A.K.); malgorzata.hawrot-paw@zut.edu.pl (M.H.-P.)

4 Department of Quality and Safety of Industrial Products, Institute of Quality and Product Management Sciences, Cracow University of Economics, Rakowicka 27, 31-510 Kraków, Poland; artur.wolak@uek.krakow.pl

* Correspondence: joanna.szyszlak@up.lublin.pl

check for updates

Citation: Szczepanik, M.; Szyszlak-Bargłowicz, J.; Zając, G.; Koniuszy, A.; Hawrot-Paw, M.; Wolak, A. The Use of Multivariate Data Analysis (HCA and PCA) to Characterize Ashes from Biomass Combustion. Energies 2021, 14, 6887. https://doi.org/10.3390/en14216887

Academic Editors: Marcin Jewiarz and Marek Wróbel

Received: 27 September 2021

Accepted: 17 October 2021

Published: 20 October 2021

Publisher's Note: MDPI stays neutral with regard to jurisdictional claims in published maps and institutional affiliations.

Copyright: (c) 2021 by the authors. Licensee MDPI, Basel, Switzerland. This article is an open access article distributed under the terms and conditions of the Creative Commons Attribution (CC BY) license (https:// creativecommons.org/licenses/by/ $4.0 /)$.

\begin{abstract}
The content of heavy metals $\mathrm{Cd}, \mathrm{Cr}, \mathrm{Cu}, \mathrm{Fe}, \mathrm{Ni}, \mathrm{Pb}$ and $\mathrm{Zn}$ in ash samples from miscanthus, oak, pine, sunflower husk, wheat straw, and willow ashes burned at 500, 600, 700, 800, 900, and $1000{ }^{\circ} \mathrm{C}$, respectively, was determined. The statistical analysis of the results was based on multivariate methods: hierarchical cluster analysis (HCA), and principal component analysis (PCA), which made it possible to classify the raw materials ashed at different temperatures into the most similar groups, and to study the structure of data variability. Using PCA, three principal components were extracted, which explain more than $88 \%$ of the variability of the studied elements. Therefore, it can be concluded that the application of multivariate statistical techniques to the analysis of the results of the study of heavy metal content allowed us to draw conclusions about the influence of biomass properties on its chemical characteristics during combustion.
\end{abstract}

Keywords: ash composition; biomass; multivariate data analysis

\section{Introduction}

All recent research works and operational experiments in the area of biomass combustion aim for the optimization of this process, and for a reduction in emissions [1,2]. Biomass combustion, despite having many advantages, raises objections of power boilers operators, such as slagging and sintering [3]. Research on the improvement of the combustion concerns mainly the reduction of gas emission by proper selection of installation parameters, and application of appropriate technology for flue gas cleaning, as well as methods of solid waste management compliant with the principles of sustainable development [4-7]. Energetic use of solid biofuels, including the increasingly popular combustion of 100\% biomass, contributes to the formation of significant amounts of ash with new properties other than ash from the combustion of coal, lignite, or biomass co-combustion. The use of the variable properties of ash from biomass combustion are limited in construction materials [8,9]; at the same time, ash from biomass combustion belong to the oldest mineral fertilizers. There are many works in the literature presenting the fertilizing properties of ashes from biomass combustion, due to the content of valuable nutrients [10-12]. Moreover, the use of biomass ash in larger doses can have a deacidifying effect, and improve the physicochemical properties of light soils [13,14].

The use of ash as a fertilizer is determined by many factors, including primarily the content of basic nutrients, and the content of heavy metals that are toxic to plants and the soil environment [15]. The total content of elements in biomass ash is influenced by 
genetic conditions, which are, to some extent, modified by environmental conditions, such as soil properties (fertilization intensity), soil $\mathrm{pH}$ and organic matter abundance, and plant species [16]. Literature analysis indicates that the content of heavy metals in biomass ash varies widely [17-19].

Heavy metals contained in ash, in addition to conditioning the use of ash as a fertilizer, may also affect the appearance of problems during biomass combustion in the furnace, promoting the phenomenon of slagging and sludge formation, or leading to corrosion of materials used in boilers [20].

Due to the use of different types of biomass in the energy sector, the actions so far should aim to undertake research that will provide a broader picture of the properties of energy waste produced with the use of biomass, with an indication of the potential risks that may arise from their inappropriate economic use.

In paper [6], the authors presented an evaluation of the influence of the type of biomass and its incineration temperature on ash content, and the content of selected heavy metal elements in the context of sustainable management of biomass ash, by using them for fertilizer purposes. The content of heavy metals in the ash studied was not excessive, and it was not considered as potentially dangerous. It was found that, with an increase in ashing temperature, the content of some elements $(\mathrm{Zn}, \mathrm{Cd}, \mathrm{Cu}, \mathrm{Pb}$ and $\mathrm{Fe})$ in the ash decreased, which proves that, at higher temperatures, they pass into the gas phase. At the same time, the content of elements which are thermally stable and less volatile metals ( $\mathrm{Cr}$ and $\mathrm{Ni}$ ) was higher, and they were the elements with which the ash were enriched as the incineration temperature increased. Moreover, a significant effect of biomass type, temperature, and the interaction of biomass type and temperature on the content of individual metals in ash was found.

However, as the previous discussion shows, ash from biomass combustion is a very heterogeneous product in terms of elemental composition. Although classical statistical analyses of large amounts of heterogeneous data can provide important information for the study of any single variable, they do not provide global knowledge about the relationships between different variables, nor do they allow grouping samples with homogeneous characteristics. However, multivariate statistical methods, such as hierarchical cluster analysis (HCA) [21] and principal component analysis (PCA) [22-24], can be used, which allow for the clustering of objects, identification of variability, and presentation of results in figures.

Literature reports indicate that HCA and PCA multivariate analyses are efficient methods to assess energy properties, and can be used to classify lignocellulosic materials [25]. Multivariate techniques have proven to be superior to conventional methods for predicting biomass fuel properties using thermogravimetry, classifying lignocellulosic wastes for bioenergy production [26], or defining a metric index of biofuel quality parameters [27]. Elemental composition, calorific value, and volatile matter content were also predicted with high accuracy [25]. The literature lacks studies using these techniques to evaluate plant biomass for solid biofuel production for heavy metal content in their ash.

The aim of this study was to select, on the basis of HCA and PCA results, plant biomass, the ashes of which, obtained at different ashing temperatures, were characterized by different contents of heavy metals. This will allow an effective and sustainable use of biomass resources, and indicate the best direction, from an environmental point of view, of the management of the resulting ashes.

\section{Materials and Methods}

\subsection{Materials}

Six typical materials used for pellet production, which are applied in low power boilers, were selected for the study. These were: oak wood pellet, pine wood pellet, miscanthus pellet, willow pellet, sunflower husk pellet, and wheat straw pellet, thus providing a range of differing ash compositions. 
Miscanthus pellets, willow pellets, and wheat straw pellets were produced in-house, while oak, pine, and sunflower husk pellets were purchased from retail chains. The basic characteristics of the pellets are presented in Table 1.

Table 1. Characteristics of the pellets used in the research.

\begin{tabular}{ccccccc}
\hline Biomass & Moisture & Ash & VM & C & H & N \\
\hline \multicolumn{7}{c}{} \\
& & \multicolumn{2}{c}{$\%$} \\
\hline Miscanthus & $6.53 \pm 0.04$ & $2.98 \pm 0.05$ & $71.9 \pm 0.1$ & $43.1 \pm 0.1$ & $6.53 \pm 0.03$ & $0.53 \pm 0.04$ \\
Oak & $5.58 \pm 0.05$ & $0.25 \pm 0.02$ & $74.6 \pm 0.2$ & $46.3 \pm 0.1$ & $6.42 \pm 0.01$ & $0.11 \pm 0.02$ \\
Pine & $4.11 \pm 0.05$ & $0.52 \pm 0.06$ & $73.4 \pm 0.2$ & $48.1 \pm 0.1$ & $4.11 \pm 0.05$ & $0.12 \pm 0.03$ \\
Sunflower husk & $7.79 \pm 0.09$ & $2.91 \pm 0.05$ & $69.5 \pm 0.2$ & $43.6 \pm 0.3$ & $6.42 \pm 0.09$ & $1.67 \pm 0.07$ \\
Wheat straw & $6.25 \pm 0.07$ & $2.97 \pm 0.04$ & $73.5 \pm 0.3$ & $43.5 \pm 0.2$ & $5.24 \pm 0.03$ & $0.52 \pm 0.07$ \\
Willow & $6.82 \pm 0.04$ & $0.38 \pm 0.07$ & $78.4 \pm 0.2$ & $45.3 \pm 0.2$ & $5.97 \pm 0.06$ & $0.54 \pm 0.03$ \\
\hline
\end{tabular}

The samples were milled in an analytical mill (IKA A11, IKA-Werke GmbH \& Co.KG, Staufen, Germany), and then sieved. Only the fraction retained on the 1.0-2.5 mm sieve was used for further analysis.

\subsection{Examination of Ash Composition}

The tested material was ashed at temperatures from $500-1000{ }^{\circ} \mathrm{C}$, with intervals of $100{ }^{\circ} \mathrm{C}$. A thermogravimeter (TGA 701, LECO Corporation, Saint Joseph, MI, USA) was used for the incineration of the material. Briefly, approximately $2 \mathrm{~g}$ of the biomass was weighed into a ceramic crucible, and subjected to heating from ambient temperature to ash-forming temperature at the heating rate of $10^{\circ} \mathrm{C} \cdot \mathrm{min}^{-1}$ in the air stream. Subsequently, the heated material was maintained at the ash-forming temperature for $4 \mathrm{~h}$. After the temperature dropped to approximately $100{ }^{\circ} \mathrm{C}$, the ash was removed, placed in a desiccator, and cooled again to ambient temperature [6].

The contents of $\mathrm{Cd}, \mathrm{Cr}, \mathrm{Cu}, \mathrm{Ni}, \mathrm{Cu}, \mathrm{Pb} \mathrm{Zn}$, and Fe were determined in the ash obtained. The XRF technique was used to determine the content of trace elements. An HDMaxine (XOS, East Greenbush, NY, USA) analyzer, based on High-Definition X-ray Fluorescence (HDXRF), was used. Since the apparatus did not require prior sample preparation, the samples were dispensed directly into measuring cups. The software of the apparatus allowed for the analysis of the acquired oscillograms [6]. The quality of the analytical results regarding their accuracy was checked using standard certified materials. In order to obtain accurate and stable experimental data, each experiment was repeated at least three times.

\subsection{Statistical Analyses}

Hierarchical cluster analysis (HCA) and principal components analysis (PCA) were used to develop the results. Calculations were performed in the Statistica ver. 13 software (TIBCO Software Inc., Palo Alto, CA, USA, 2017).

HCA methods make it possible to assign objects (raw materials and temperatures) to groups within which the most similar objects will be found. The grouping can be helpful to study the structure of the community, and to detect regularities occurring for the obtained clusters. The results are presented in dendrograms, which show the hierarchical structure of groups due to decreasing similarity between the clusters.

PCA can be used to determine the relationship between multiple primary (input) variables, and to identify factors common to them. By reducing the number of primary variables and replacing them with components that significantly explain their variation, PCA allows for the description of occurring processes and phenomena with the maximum amount of information. Assuming that the first few components contain a significant amount of the variability of the original data set, they can together explain almost all of the variability in the data, and thus simplify the interpretation of the results. 


\section{Results and Discussion}

The heavy metal content of the biomass studied varied within very wide limits. The differences between particular types of organic material, even of the same type, were of orders of magnitude. The results of the analyses are summarized in Table 2.

Table 2. Average contents of the studied heavy metals with distinction of biomass types and ashing temperatures.

\begin{tabular}{|c|c|c|c|c|c|c|c|c|c|}
\hline Biomass & Temp & Code & $\mathrm{Cd}$ & $\mathrm{Cr}$ & $\mathrm{Cu}$ & $\mathrm{Fe}$ & $\mathbf{N i}$ & $\mathrm{Pb}$ & $\mathrm{Zn}$ \\
\hline & ${ }^{\circ} \mathrm{C}$ & & \multicolumn{7}{|c|}{$\mathrm{mg} \cdot \mathrm{kg}^{-1}$} \\
\hline Miscanthus & 500 & M5 & 7.68 & 25.7 & 58.77 & 5390 & 16.4 & 9.69 & 716 \\
\hline Oak & 500 & O5 & 8.26 & 22.41 & 307 & 4059 & 19.17 & 12.21 & 300 \\
\hline Pine & 500 & P5 & 8.06 & 18.87 & 203 & 4250 & 21.69 & 12.91 & 430 \\
\hline Sunflower husk & 500 & S5 & 9.93 & 50.09 & 358 & 5736 & 59.37 & 6.78 & 647 \\
\hline Wheat straw & 500 & Ws5 & 5.42 & 32.25 & 72.54 & 5315 & 14.17 & 8.52 & 336 \\
\hline Willow & 500 & W5 & 7.5 & 39.93 & 190 & 1568 & 75.51 & 10.23 & 922 \\
\hline Miscanthus & 600 & M6 & 6.36 & 27.14 & 58.55 & 4271 & 16.82 & 9.36 & 617 \\
\hline Oak & 600 & O6 & 5.92 & 34.92 & 304 & 3665 & 35.08 & 11.18 & 251 \\
\hline Pine & 600 & P6 & 7.16 & 28.3 & 196 & 3814 & 31.67 & 12.04 & 401 \\
\hline Sunflower husk & 600 & S6 & 7.24 & 53.95 & 333 & 4200 & 61.77 & 5.93 & 412 \\
\hline Wheat straw & 600 & Ws6 & 4.91 & 43.6 & 57.94 & 4450 & 17.44 & 7.01 & 235 \\
\hline Willow & 600 & W6 & 7.13 & 44.45 & 155 & 1485 & 83 & 9.27 & 758 \\
\hline Miscanthus & 700 & M7 & 4.91 & 30.99 & 57.24 & 3781 & 18.67 & 7.6 & 592 \\
\hline Oak & 700 & O7 & 4.98 & 38.19 & 266 & 3534 & 50.37 & 9.9 & 155 \\
\hline Pine & 700 & P7 & 6.25 & 32.61 & 151 & 3566 & 51.34 & 10.14 & 253 \\
\hline Sunflower husk & 700 & S7 & 6.57 & 59.39 & 284 & 3572 & 65.71 & 4.89 & 383 \\
\hline Wheat straw & 700 & Ws7 & 4.31 & 48.75 & 54.24 & 3944 & 28.49 & 6.46 & 204 \\
\hline Willow & 700 & W7 & 6.9 & 55.8 & 141 & 1452 & 89.33 & 8.43 & 699 \\
\hline Miscanthus & 800 & M8 & 4.12 & 33.33 & 55.83 & 2803 & 18.73 & 7.42 & 538 \\
\hline Oak & 800 & O8 & 4.85 & 40.2 & 242 & 3199 & 62.38 & 7.86 & 67.26 \\
\hline Pine & 800 & P8 & 4.49 & 36.88 & 134 & 3141 & 56.58 & 8.58 & 210 \\
\hline Sunflower husk & 800 & S8 & 4.88 & 69.76 & 263 & 2934 & 68.9 & 4.73 & 149 \\
\hline Wheat straw & 800 & Ws8 & 4.04 & 51.29 & 53.03 & 3226 & 31.13 & 5.93 & 185 \\
\hline Willow & 800 & W8 & 4.55 & 60.14 & 131 & 1338 & 96.67 & 7.55 & 550 \\
\hline Miscanthus & 900 & M9 & 3.65 & 37.11 & 54.74 & 2669 & 21.03 & 5.58 & 402 \\
\hline Oak & 900 & O9 & 3.9 & 44.18 & 220.33 & 2242 & 66.83 & 5.94 & 46.29 \\
\hline Pine & 900 & P9 & 4.17 & 40.88 & 102 & 2591 & 59.49 & 6.74 & 201 \\
\hline Sunflower husk & 900 & S9 & 3.62 & 81.92 & 254.67 & 2859 & 94.23 & 4.53 & 53.97 \\
\hline Wheat straw & 900 & Ws9 & 3.61 & 57.46 & 46.48 & 2593 & 45.08 & 4.2 & 163 \\
\hline Willow & 900 & W9 & 4.11 & 71.53 & 129 & 871 & 116.67 & 5.16 & 444 \\
\hline Miscanthus & 1000 & M10 & 3.17 & 50.43 & 51.27 & 1928 & 21.49 & 5.43 & 155.67 \\
\hline Oak & 1000 & $\mathrm{O} 10$ & 3.45 & 73.52 & 164.67 & 1603 & 84.56 & 5.38 & 31.69 \\
\hline Pine & 1000 & P10 & 3.45 & 65.95 & 85.63 & 1764 & 66.26 & 6.04 & 95.3 \\
\hline Sunflower husk & 1000 & S10 & 3.36 & 91.47 & 215 & 2788 & 106.67 & 3.76 & 22.13 \\
\hline Wheat straw & 1000 & Ws10 & 3.51 & 68.02 & 41.96 & 2356 & 50.32 & 3.45 & 152.67 \\
\hline Willow & 1000 & W10 & 3.5 & 96.90 & 95.1 & 712.67 & 126.33 & 4.71 & 236 \\
\hline
\end{tabular}

Through analyzing the data presented in Table 2, it was observed that, with increasing ashing temperature, the content of elements such as $\mathrm{Cr}$ and $\mathrm{Ni}$ in ash increased, while $\mathrm{Cd}$, $\mathrm{Pb}, \mathrm{Cu}, \mathrm{Zn}$, and $\mathrm{Fe}$ decreased. It should be noted, however, that, for ashes from different types of biomass, these changes occurred with different dynamics. Changes in $\mathrm{Cr}$ content in miscanthus ash were characterized by the lowest dynamics among the materials studied $\left(25.7-50.43 \mathrm{mg} \cdot \mathrm{kg}^{-1}\right)$, while the highest dynamics of changes of this element were found in willow ash (39.93-96.90 $\left.\mathrm{mg} \cdot \mathrm{kg}^{-1}\right)$. Miscanthus ash was also characterized by low dynamics of changes in Ni content $\left(16.4-21.49 \mathrm{mg} \cdot \mathrm{kg}^{-1}\right)$, while the highest range of changes in this element content was observed in oak $\left(19.17-84.56 \mathrm{mg} \cdot \mathrm{kg}^{-1}\right)$. In the case of elements whose content decreased with increasing ashing temperatures, the highest dynamics of change 
were found in relation to $\mathrm{Zn}$ content. The most noticeable was the change in the content of this element in the ash of sunflower husk (647-22.12 mg. $\left.\mathrm{kg}^{-1}\right)$. The dynamics of changes in $\mathrm{Cu}$ content in the examined ashes were very different. Wheat straw and miscanthus ashes were characterized by very low dynamics of changes in $\mathrm{Cu}$ content $\left(72.54-41.96 \mathrm{mg} \cdot \mathrm{kg}^{-1}\right.$ and $58.77-51.27 \mathrm{mg} \cdot \mathrm{kg}^{-1}$, respectively), while pine, oak and sunflower husk ashes showed similar high dynamics (203-85.63 $\mathrm{mg} \cdot \mathrm{kg}^{-1}, 307-164.67 \mathrm{mg} \cdot \mathrm{kg}^{-1}$ and $358-215 \mathrm{mg} \cdot \mathrm{kg}^{-1}$ ). The highest dynamics were found for willow ashes (190-95.1 mg. $\mathrm{kg}^{-1}$ ). In the case of changes in $\mathrm{Pb}$ content, sunflower husk and willow ashes showed similar dynamics, which were low (6.78-3.76 and $\left.10.23-4.71 \mathrm{mg} \cdot \mathrm{kg}^{-1}\right)$, whereas ashes from the other materials showed similar higher dynamics of change. The concentration of $\mathrm{Cd}$ changed to the smallest extent in wheat straw ash $\left(5.42-3.51 \mathrm{mg} \cdot \mathrm{kg}^{-1}\right)$, and to the greatest extent in sunflower husk ash (9.93-3.36 $\left.\mathrm{mg} \cdot \mathrm{kg}^{-1}\right)$; other ashes had similar dynamics of change in the content of this element. The dynamics of changes in Fe content were lowest in ash of willow (1568-712.67 mg $\cdot \mathrm{kg}^{-1}$ ), and highest in miscanthus ash (5390-1928 $\left.\mathrm{mg} \cdot \mathrm{kg}^{-1}\right)$.

Moreover, it was observed, that among the ashes studied, sunflower husk ash was characterized by the highest content of $\mathrm{Cd}, \mathrm{Cr}, \mathrm{Cu}$, and $\mathrm{Fe}$, willow ash contained the most $\mathrm{Ni}$ and $\mathrm{Zn}$, and pine ash contained the most $\mathrm{Pb}$. On the other hand, miscanthus ash was characterized by the lowest content of $\mathrm{Cr}$ and $\mathrm{Ni}$, oak ash contained the least $\mathrm{Zn}$, and wheat straw ash contained the least $\mathrm{Cd}, \mathrm{Cu}$, and $\mathrm{Pb}$. As stated in [28], it is essential to have a better understanding of the origin of trace elements, as well as knowledge about which trace elements are most critical for favorable biomass recycling schemes. It should be noted that a high content of heavy metals in biomass ash makes recycling difficult.

In view of the above, an attempt was made to evaluate the biomass studied, with respect to heavy metal contents, to group it according to these characteristics, and to indicate the most important indicators determining this division.

A multivariate HCA technique was used to classify and cluster ash samples from different types of biomass, based on the content of heavy metals tested, which represent the main characteristics of the fuel.

Figure 1 shows a dendrogram, which is a graphical representation of the clustering process. It shows the three clusters obtained after applying Ward's agglomeration method, and choosing the Euclidean metric as the distance measure. Ward's agglomeration method consists of minimizing the sum of squared deviations within the clusters. At each stage, a pair is selected from among all possible combinable pairs of clusters, resulting in a cluster with minimal differentiation after combining. The distance between the samples reflects the similarity (close) or dissimilarity (distant) of their properties, which is useful for determining the similarities or differences between them, in terms of metal content in the ashes.

The most similar group (the least diverse on Figure 1) consists of sunflower husk, willow, oak, and pine ashed at the highest temperatures. A separate cluster is formed by oak, pine, and sunflower husk burnt mostly at temperatures ranging from 500 to $700{ }^{\circ} \mathrm{C}$ (in the case of oak, this range also included $800^{\circ} \mathrm{C}$ ). The third group consists of miscanthus, wheat straw, and pine (temperatures ranging from 800 to $900{ }^{\circ} \mathrm{C}$ ).

The different agglomeration methods in the HCA method may result in different clusters. Therefore, the HCA method is often used for preliminary data analysis.

The extraction of so-called principal components in PCA is possible when there are correlations between the primary variables (heavy metal contents) [29]. In the correlation matrix (Table 3), there are strong correlations between $\mathrm{Cr}$ and $\mathrm{Ni}$ (positive), and $\mathrm{Cr}$ and $\mathrm{Pb}$ (negative). Moderate correlations can also be seen between $\mathrm{Cd}$ and the other variables (except $\mathrm{Ni}$ ), and moderate correlations between $\mathrm{Fe}$ and $\mathrm{Ni}$, as well as $\mathrm{Cr}$ and $\mathrm{Fe}$.

The relationships (factor loadings) between the elemental content of ash and the PC1 and PC2 components are presented in Figure 2. The axes of the coordinate system are the PC1 and PC2 components. The position of the ends of the vectors near the unit circle indicates that much of the information contained in the variables is carried by the principal components. The position of the ends of the vectors relative to the axes (PC1 and PC2) 
is consistent with the signs of the factor loadings (Table 3). It can be seen (Figure 2) that the variable Fe is positively correlated with the components of PC1 and PC2, while the variables $\mathrm{Cr}$ and $\mathrm{Ni}$ are negatively correlated with the components of PC1 and PC2. The other variables $(\mathrm{Cd}, \mathrm{Pb}, \mathrm{Cu}$, and $\mathrm{Zn})$ are positively correlated with component $\mathrm{PC} 1$, and negatively correlated with component PC2. Nearby variables are positively correlated (e.g., $\mathrm{Cr}$ and $\mathrm{Ni}, \mathrm{Zn}$ and $\mathrm{Cd}$ ), and opposite variables are negatively correlated (e.g., $\mathrm{Cr}$ and $\mathrm{Fe}$, $\mathrm{Cr}$ and $\mathrm{Cd}$ ). Perpendicular vectors indicate a lack of correlation (e.g., $\mathrm{Cu}$ and $\mathrm{Cr}$ variables, $\mathrm{Ni}$ and $\mathrm{Zn}$ variables).

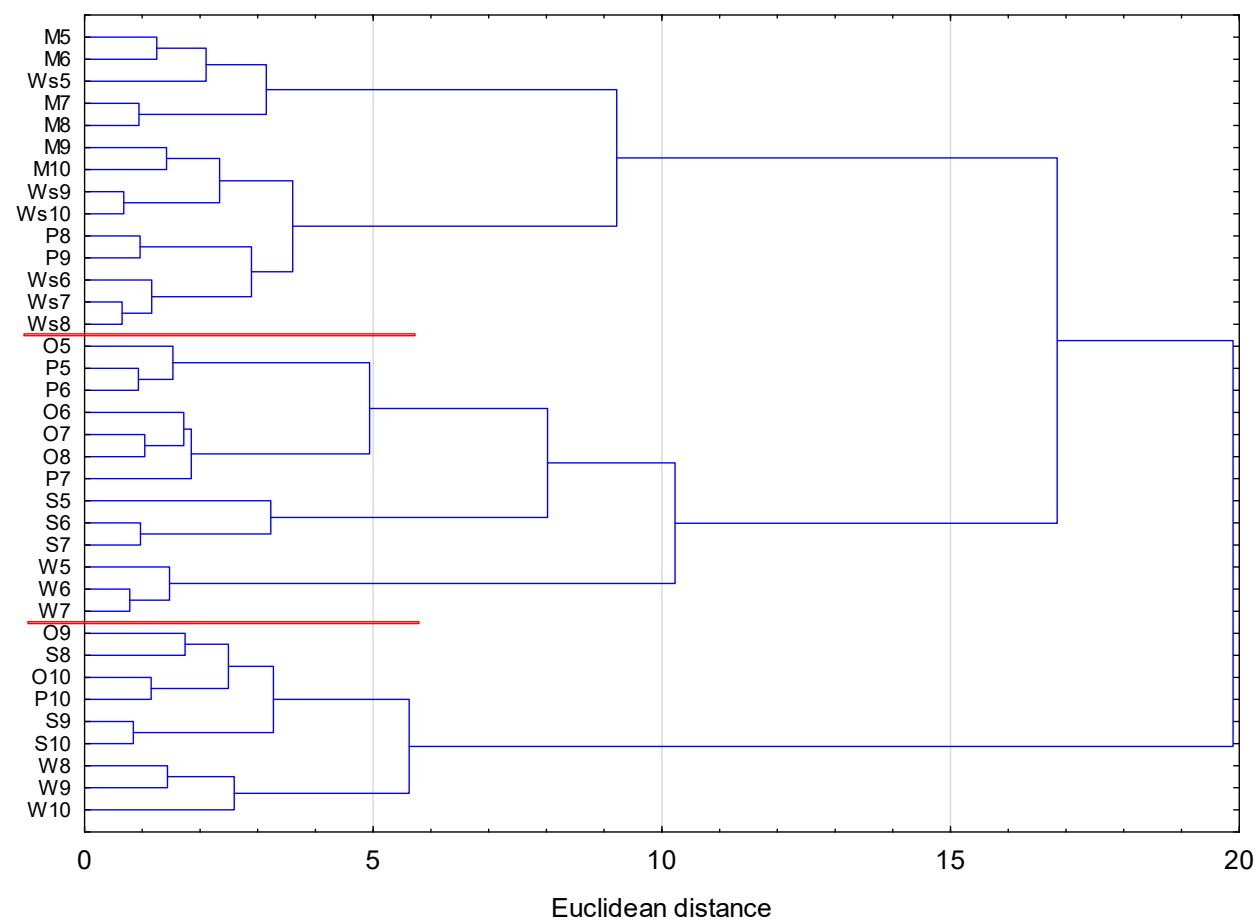

Figure 1. Dendrogram of raw materials and temperatures obtained from HCA.

Table 3. Correlation coefficients between heavy metal contents.

\begin{tabular}{ccccccc}
\hline & $\mathbf{C d}$ & $\mathbf{C r}$ & $\mathbf{C u}$ & $\mathbf{F e}$ & $\mathbf{N i}$ & $\mathbf{P b}$ \\
\hline $\mathrm{Cr}$ & $-0.53^{*}$ & & & & & \\
$\mathrm{Cu}$ & $0.50^{*}$ & 0.04 & & & & \\
$\mathrm{Fe}$ & $0.54^{*}$ & $-0.57^{*}$ & 0.21 & & & \\
$\mathrm{Ni}$ & -0.22 & $0.79^{*}$ & 0.28 & $-0.68^{*}$ & & \\
$\mathrm{~Pb}$ & $0.67^{*}$ & $-0.79^{*}$ & 0.21 & $0.37^{*}$ & $-0.42 *$ & \\
$\mathrm{Zn}$ & $0.66^{*}$ & $-0.40^{*}$ & -0.05 & 0.10 & -0.10 & $0.44^{*}$ \\
\hline${ }^{*}$ indicates significance at the significance level $\left.<0.05\right)$.
\end{tabular}

Table 4. Factor loadings of elements and selected principal components (PC1, PC2, PC3).

\begin{tabular}{cccc}
\hline Element & PC1 & PC2 & PC3 \\
\hline $\mathrm{Cd}$ & 0.81 & -0.52 & -0.04 \\
$\mathrm{Cr}$ & -0.90 & -0.29 & 0.06 \\
$\mathrm{Cu}$ & 0.19 & -0.79 & 0.54 \\
$\mathrm{Fe}$ & 0.73 & 0.17 & 0.51 \\
$\mathrm{Ni}$ & -0.69 & -0.66 & -0.16 \\
$\mathrm{~Pb}$ & 0.84 & -0.13 & -0.13 \\
$\mathrm{Zn}$ & 0.55 & -0.30 & -0.70 \\
Eigenvalue & 3.52 & 1.56 & 1.10 \\
Variance \% & 50.25 & 22.23 & 15.65 \\
Cumulative variance \% & 50.25 & 72.48 & 88.13 \\
\hline
\end{tabular}




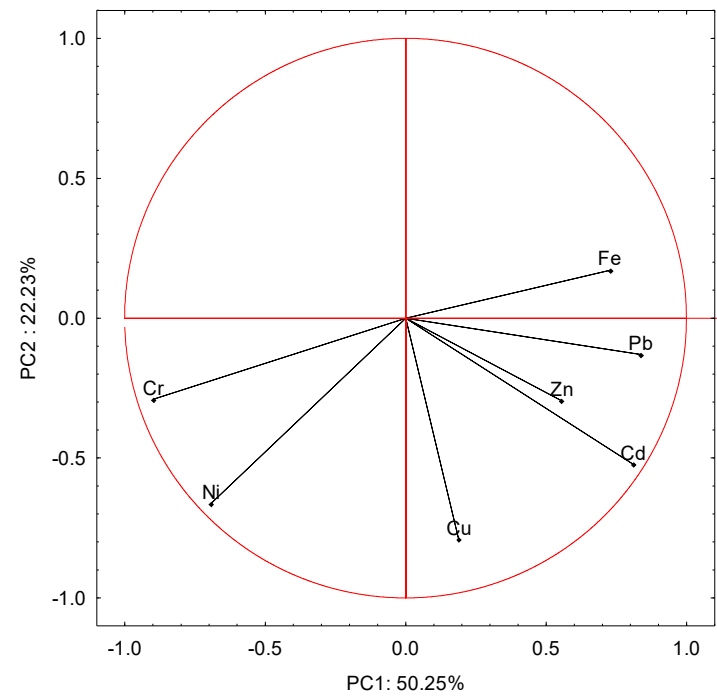

Figure 2. PCA results (position of loadings vectors relative to PC1 and PC2).

Figure 3 shows the observations (distinguished by biomass type and incineration temperatures) placed on the plane spanned by the PC1 and PC2 components. It is found that the PC1 component classifies the observations with respect to the incineration temperatures. It can be observed that observations corresponding to lower incineration temperatures, i.e., 500,600 , and (mostly) $700{ }^{\circ} \mathrm{C}$ have positive PC1 coordinates. The observations corresponding to the highest incineration temperatures $\left(1000,900\right.$, and $800{ }^{\circ} \mathrm{C}$, except pine and miscanthus) have negative PC1 coordinates. Additionally, a split in the data relative to the PC2 component can be seen. Observations corresponding to the willow and sunflower husk biomass have negative values of the PC2 component, and are located close to each other for successive temperatures. Observations corresponding to oak and pine biomasses are in the next lane (they have both positive and negative values of PC2), whereas observations corresponding to wheat straw and miscanthus raw materials have positive values of PC2 (points are in the upper lane).

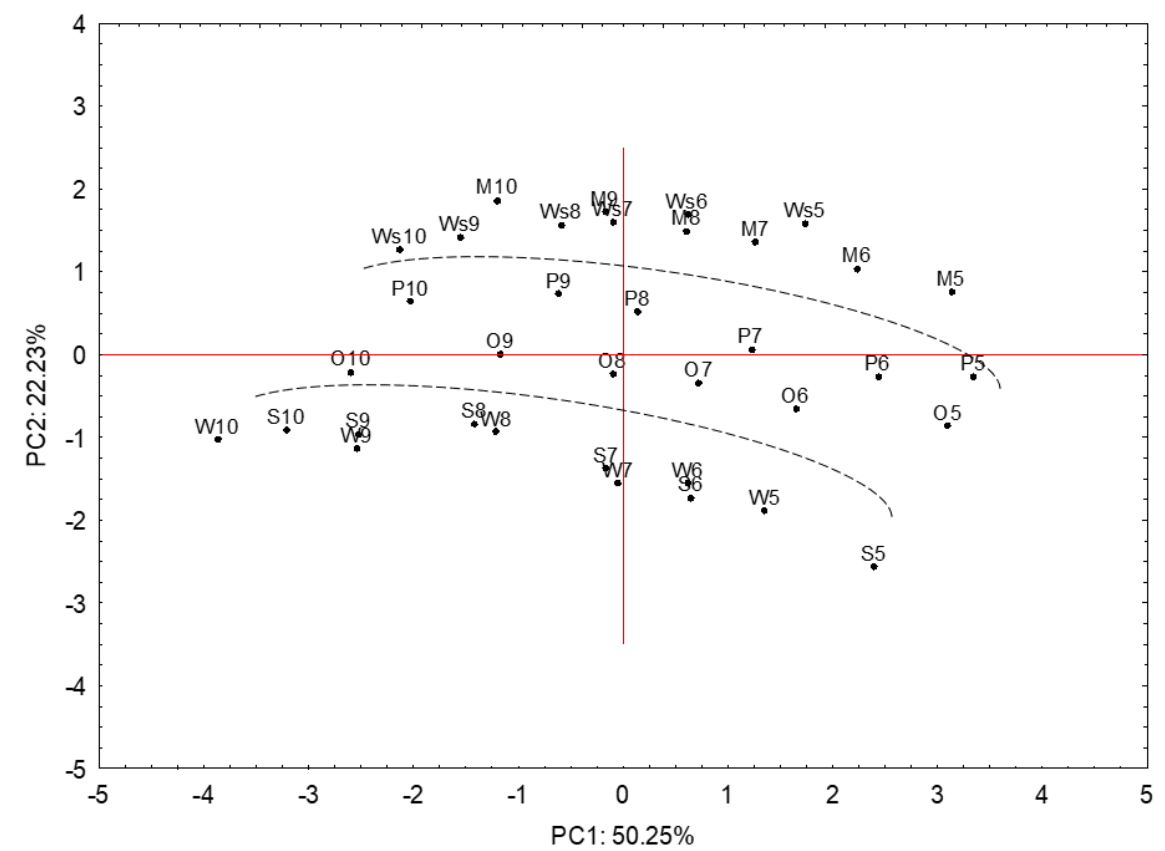

Figure 3. Observations at PC1 and PC2. 
Biomass classification based on multivariate data analysis methods has also been attempted by other researchers. A previous work [31] showed the grouping and relations between groups on score plots. An arrangement of biomass properties in a variable biomass spectrum has been demonstrated, and correlations between the biomass properties and the species groups were highlighted. Moreover, it has been proven that ash content is an important factor that differentiates the energy properties of biomass and the fuel energy content between grades, and between assortments.

\section{Conclusions}

The multivariate HCA and PCA methods used in this study proved to be effective tools for analyzing the results of chemical composition of ash from different types of biomass.

HCA enabled the grouping of the examined biomass and incineration temperatures into clusters, which included the ashes that were least differentiated among themselves. On this basis, three groups of biomass and ashing temperatures were distinguished, which were most similar in terms of variability of the content of heavy metals studied.

PCA allowed for the reduction in the set of seven variables (elements) initially used to characterize the ash composition into three principal components, helpful in structure identification, explaining more than $88 \%$ of the variation in the content of the studied elements. Regularities were observed in the pattern of data for changing temperatures relative to PC1 (lower ashing temperatures corresponded to higher PC1 values, and higher temperatures corresponded to lower PC1 values). In addition, it was possible to group biomass and ashing temperatures for which the elemental content was similar. Three groups of observations (three groups of most similar materials) were distinguished: sunflower husk and willow (lowest PC2 values); pine and oak (moderate PC2 values); and wheat straw and miscanthus (highest PC2 values).

Although the results of the HCA and PCA methods are not completely consistent (they are essentially different methods of analysis), both methods revealed the similarity between wheat straw and miscanthus raw materials, which may be a premise for further research.

Author Contributions: Conceptualization, M.S.; methodology, M.S., G.Z. and J.S.-B.; validation, M.S.; formal analysis, M.S.; investigation, G.Z. and J.S.-B.; resources, G.Z. and J.S.-B.; data curation, J.S.-B.; writing—original draft preparation, J.S.-B.; M.S. and G.Z.; writing—review and editing, A.K., M.H.-P. and A.W.; visualization, M.S.; supervision, J.S.-B.; project administration, G.Z.; funding acquisition, A.K. and M.H.-P. All authors have read and agreed to the published version of the manuscript.

Funding: APC funded from the 'Excellent science' program of the Ministry of Science and Higher Education as a part of the contract no. DNK/SP/465641/2020 "The role of the agricultural engineering and environmental engineering in the sustainable agriculture development". The research publication was financed with subsidies for maintaining the research capacity granted to University of Life Sciences in Lublin, Cracow University of Economics and to West Pomeranian University of Technology.

Data Availability Statement: The data presented in this study are available on request from the corresponding author.

Conflicts of Interest: The authors declare no conflict of interest. The funders had no role in the design of the study; in the collection, analyses, or interpretation of data; in the writing of the manuscript; or in the decision to publish the results.

\section{References}

1. Jasinskas, A.; Mieldažys, R.; Jotautienè, E.; Domeika, R.; Vaiciukevičius, E.; Marks, M. Technical, Environmental, and Qualitative Assessment of the Oak Waste Processing and Its Usage for Energy Conversion. Sustainability 2020, 12, 8113. [CrossRef]

2. Jandačka, J.; Holubčík, M. Emissions Production from Small Heat Sources Depending on Various Aspects. Mob. Netw. Appl. 2020, 25, 904-912. [CrossRef]

3. Yao, X.; Zhao, Z.; Li, J.; Zhang, B.; Zhou, H.; Xu, K. Experimental Investigation of Physicochemical and Slagging Characteristics of Inorganic Constituents in Ash Residues from Gasification of Different Herbaceous Biomass. Energy 2020, 198, 117367. [CrossRef]

4. Vassilev, S.V.; Baxter, D.; Andersen, L.K.; Vassileva, C.G. An Overview of the Composition and Application of Biomass Ash.: Part 2. Potential Utilisation, Technological and Ecological Advantages and Challenges. Fuel 2013, 105, 19-39. [CrossRef] 
5. Zając, G.; Szyszlak-Bargłowicz, J.; Dudziak, A.; Kuranc, A.; Wasilewski, J. Ash Composition and Deposition Tendencies of Selected Biomass Types; Department of Machinery Exploitation and Management of Production Processes: Lublin, Poland, 2017; ISBN 839374332X.

6. Zając, G.; Szyszlak-Bargłowicz, J.; Szczepanik, M. Influence of Biomass Incineration Temperature on the Content of Selected Heavy Metals in the Ash Used for Fertilizing Purposes. Appl. Sci. 2019, 9, 1790. [CrossRef]

7. Jandacka, J.; Caban, J.; Nieoczym, A.; Holubcik, M.; Vrabel, J. Possibilities of Using Wood Waste for the Production of Fuel Briquettes. PRZEMYSL Chem. 2021, 100, 367-374.

8. Carević, I.; Baričević, A.; Štirmer, N.; Šantek Bajto, J. Correlation between Physical and Chemical Properties of Wood Biomass Ash and Cement Composites Performances. Constr. Build. Mater. 2020, 256, 119450. [CrossRef]

9. Munawar, M.A.; Khoja, A.H.; Naqvi, S.R.; Mehran, M.T.; Hassan, M.; Liaquat, R.; Dawood, U.F. Challenges and Opportunities in Biomass Ash Management and Its Utilization in Novel Applications. Renew. Sustain. Energy Rev. 2021, 150, 111451. [CrossRef]

10. Ciesielczuk, T.; Kusza, G.; Nems, A. Fertilization with Biomass Ashes as a Source of Trace Elements for Soils. Environ. Prot. Nat. Resour. 2011, 49, 219-227.

11. Maschowski, C.; Zangna, M.C.; Trouvé, G.; Gieré, R. Bottom Ash of Trees from Cameroon as Fertilizer. Appl. Geochem. 2016, 72, 88-96. [CrossRef]

12. Pesonen, J.; Kuokkanen, V.; Kuokkanen, T.; Illikainen, M. Co-Granulation of Bio-Ash with Sewage Sludge and Lime for Fertilizer Use. J. Environ. Chem. Eng. 2016, 4, 4817-4821. [CrossRef]

13. Schiemenz, K.; Eichler-Löbermann, B. Biomass Ashes and Their Phosphorus Fertilizing Effect on Different Crops. Nutr. Cycl. Agroecosys. 2010, 87, 471-482. [CrossRef]

14. Meller, E.; Bilenda, E. Effects of Biomass Ash on the Physicochemical Properties of Light Soil. Energy Policy J. 2012, 15, $287-292$.

15. Poluszyńska, J.; Ślęzak, E. Characteristics of Fly Ash from the Combustion of Biomass as Stabilizer of Sewage Sludge. Sci. Works Inst. Ceram. Build. Mater. 2015, 8, 71-78.

16. Haustein, E.; Grabarczyk, L. The Biomass and Coal Co-Incineration Impacts on the Selected Properties of Fly Ashes. Energy Policy J. 2012, 15, 87-101.

17. Vassilev, S.V.; Baxter, D.; Andersen, L.K.; Vassileva, C.G. An Overview of the Composition and Application of Biomass Ash. Part 1. Phase-Mineral and Chemical Composition and Classification. Fuel 2013, 105, 40-76. [CrossRef]

18. Vassilev, S.V.; Vassileva, C.G.; Baxter, D. Trace Element Concentrations and Associations in Some Biomass Ashes. Fuel 2014, 129, 292-313. [CrossRef]

19. Zając, G.; Szyszlak-Bargłowicz, J.; Gołębiowski, W.; Szczepanik, M. Chemical Characteristics of Biomass Ashes. Energies 2018, 11, 2885. [CrossRef]

20. Eriksson, J.-E.; Khazraie, T.; Hupa, L. Different Methods for the Characterization of Ash Compositions in Co-Firing Boilers; Springer: Berlin/Heidelberg, Germany, 2018; pp. 253-263.

21. Izenman, A.J. Modern Multivariate Statistical Techniques; Springer Texts in Statistics; Springer: New York, NY, USA, 2008.

22. Jolliffe, I.T.; Cadima, J. Principal Component Analysis: A Review and Recent Developments. Philos. Trans. R. Soc. Math. Phys. Eng. Sci. 2016, 374, 20150202. [CrossRef] [PubMed]

23. Tabachnick, B.G.; Fidell, L.S. Using Multivariate Statistics, 7th ed.; Pearson: Boston, MA, USA, 2019 ; Volume 5.

24. Trendafilov, N.; Gallo, M. Principal component analysis (PCA). In Multivariate Data Analysis on Matrix Manifolds: (With Manopt); Trendafilov, N., Gallo, M., Eds.; Springer International Publishing: Cham, Switzerland, 2021; pp. 89-139. ISBN 978-3-030-76974-1.

25. Strandberg, A.; Holmgren, P.; Broström, M. Predicting Fuel Properties of Biomass Using Thermogravimetry and Multivariate Data Analysis. Fuel Process. Technol. 2017, 156, 107-112. [CrossRef]

26. de Paula Protásio, T.; Bufalino, L.; Junior, M.G.; Tonoli, G.H.D.; Trugilho, P.F. Multivariate Techniques Applied to Evaluation of Lignocellulosic Residues for Bioenergy Production. Ciênc. Florest. 2013, 23, 771-781.

27. Sgarbossa, A.; Costa, C.; Menesatti, P.; Antonucci, F.; Pallottino, F.; Zanetti, M.; Grigolato, S.; Cavalli, R. A Multivariate SIMCA Index as Discriminant in Wood Pellet Quality Assessment. Renew. Energy 2015, 76, 258-263. [CrossRef]

28. Tao, G.; Lestander, T.A.; Geladi, P.; Xiong, S. Biomass Properties in Association with Plant Species and Assortments I: A Synthesis Based on Literature Data of Energy Properties. Renew. Sustain. Energy Rev. 2012, 16, 3481-3506. [CrossRef]

29. Jolliffe, I.T. (Ed.) Principal Component Analysis for Time Series and Other Non-Independent Data. In Principal Component Analysis; Springer Series in Statistics; Springer: New York, NY, USA, 2002; pp. 299-337. ISBN 978-0-387-22440-4.

30. Yeomans, K.A.; Golder, P.A. The Guttman-Kaiser Criterion as a Predictor of the Number of Common Factors. J. R. Stat. Soc. Ser. Stat. 1982, 31, 221-229. [CrossRef]

31. Voshell, S.; Mäkelä, M.; Dahl, O. A Review of Biomass Ash Properties towards Treatment and Recycling. Renew. Sustain. Energy Rev. 2018, 96, 479-486. [CrossRef] 